between observation and hypothesis it is well worth reading. Some of the theories advanced I regard as highbrow science fiction, I particularly dislike his interpretation of the spreading of Proteus vulgaris. It must be admitted, however, that there is nothing so far published that effectively disposes of them and this edition when compared with the earlier one shows the author to be adaptable enough to adjust to future discoveries as they are made.

The book is notably well produced and the photographs are as good as in the original papers quoted.

W.H.H.

\section{ANATOMY AND PHYSIOLOGY FOR NURSES}

By W. P. Gowland, M.D., F.R.C.S., and JohN CAIRNEY, D.Sc., M.D., F.R.A.C.S. Fourth edition. Pp. 462. Christchurch, New Zealand: N. M. Peryer Ltd. 1955. 45 s.

Here is a book which needs no introduction, previous editions being already well known to the nursing profession. Many of the chapters have been re-written in order to bring the subject matter thoroughly up to date. In addition, the type has been re-set, resulting in a marked improvement in general appearance. There are many clear illustrations to supplement the text.

The authors have written this book primarily for the student nurse, although the chapters on "The Distribution of the Spinal Nerves to the Limbs' and 'The Neuro-Physiology of Vision' have been included for the benefit of students of physiotherapy and orthoptics.

It is unfortunate that the price of $45 \mathrm{~s}$. puts this volume rather out of reach of the average student nurse, as it has already proved itself worthy of more general use in schools of nursing.

\section{R.S.}

\section{KINESIOLOGY OF THE HUMAN BODY}

By Arthur Steindler, M.D., (Hon.) F.R.C.S., F.A.C.S., F.I.C.S. Pp. xxiv +708 , illustrated. Oxford: Blackwell Scientific Publications Ltd. 1955. £7 2s. 6d.

In the present work Dr. Steindler elaborates the ideas which he first propounded in his book 'The Mechanics of Normal and Pathological Locomotion.' He is concerned to show that kinesiology, which in his own words 'presents bodily motion as a special case in mechanics,' is a valuable and possibly an indispensable basis for the study of disorders of locomotion. To that end he now attempts an ambitious project-the integration of the theory of kinesiology with the observed facts of various pathological conditions and with the methods for their correction. The first part of the book deals with the physical properties of bone, cartilage connective tissue and muscle in relation to the mechanics and pathomechanics of joint and muscle function. In the second and third parts of the book are considered the mechanics of special regions-spine, pelvis, thorax and limbs-while the⿳八人口 gait is considered separately in the fourth part.

The book clearly represents the result of a great deal of very painstaking work and certainly itsc detailed consideration of applied anatomy and mechanics forms a very helpful basis for the under-s? standing of locomotor disorders. Very helpful too are those sections dealing with reconstructive pro등 cedures for the upper and lower limbs. However $\overline{\bar{n}}$. the bridge connecting the purely mechanical con $-\vec{\nabla}$ siderations to those concerned with pathologica $\mathbb{Q}$ conditions remains rather tenuous and the value of Dr. Steindler's more detailed calculations in theirapplication to clinical practice is still a little doubtful. Indeed, in some sections the attempted $\vec{r}$ application of the one to the other appears somewhat forced. It is doubtful whether a purely mechanistico study can serve as a basis for the interpretation of locomotor disorders unless, reinforced by a large $e_{\omega}$. addition of biological theory.

Although the author presents his facts clearly he山 presents so many that the book has to be read? slowly and with concentration to assimilate the mass of information contained in it. The task is r made easier by the high standard of production and of illustration, though the text is marred occasionalyys by a few tiresome misprints.

\section{MODERN TRENDS IN BLOOD DISEASES}

Edited by John F. WiLkinson, M.D., M.Sc., Ph.\&̊․ F.R.C.P., F.R.I.C. Pp. viii + 359, with illustrations, two in colour. London: Butter worth \& Co., Ltd. I 955 . $£ 3$ ss.

Before embarking on any criticism of this book it must be stated that it is a valuable contribution to modern haematological literature. It is beautifully produced and well illustrated and should be on the shelves of anyone interested in haematology.

According to its editor, the book is a guide t $\vec{\sigma}$ the present trends of the more important clinica $B$ and experimental investigations and research that during the last 20 years, have been pursued activelyo in one of the biggest branches of medicine-that dealing with diseases of the blood and blood $\frac{0}{3}$ forming organs.' The casual reader glancing at the table of contents might be forgiven for assuming that almost all these advances had been made in the hospitals of Manchester, Derby, Glasgow andP Newcastle upon Tyne, for I I of the 15 chapters have been written by workers in these hospitals. This parochial approach seems regrettable, for, although the work done in these hospitals has been considero able, yet it is a pity that no contributions should have been included from the Oxford or Cambridgs Schools of Haematology, or from the British Post graduate School, to mention only three other centres in this country where active research in haematologyw has been carried on for a number of years. Nor arE there any contributions from the continentab schools. American workers have fared better, thre chapters being contributed by eminent Americate haematologists. So much for the selection of 
authors. With regard to the selection of subjects, there is a brilliant review of iron metabolism by Professor C. V. Moore and Dr. Ruberia Dubach which alone makes the book worth buying. Other excellent contributions are those on porphyrins by Professor Rimmington, haemolytic anaemia by Lt.-Col. Crosby and Professor Dameshek, and on the anaemia of infection by Professors Cartwright and Wintrobe. As would be expected, the leukaemias are well dealt with by Dr. John F. Wilkinson and his colleagues, and the reticuloses by Dr. M. C. G. Israëls. Other valuable chapters have been written by Mr. D. Ll. Griffiths on bone changes in blood diseases, by Professor Wilfred Gaisford on paediatric haematology, by Mr. Dennis Dawson on ophthalmoscopic appearance in blood disease, by Dr. Alexander Brown on anticoagulant therapy, and by Dr. F. Stratton on iso-immunization to blood group antigens. It may be wondered whether there is any place in a book like this for a long section on haematological technique, including details of such procedures as red and white cell counts and haemoglobin estimations. There is nothing new in this section and it, and the section on dermatological aspects of blood diseases, might well have given place to some recent advances, such as the studies on the different types of haemoglobin or on blood coagulation, which receive scant attention in this book. No two people will agree, however, as to what should be included in a book of this sort and, in spite of these criticisms, the editor is to be congratulated on having produced such a very useful and informative volume.

\section{M.R.C. Special Report No. 289}

\section{STUDIES ON EXPENDITURE OF ENERGY AND CONSUMPTION OF FOOD BY MINERS AND CLERKS, FIFE, SCOTLAND, 1952}

By R. C. Garry, R. Passmore, Grace M. Warnock and J. V. G. A. Durnin. Pp. vi +69 , with ro illustrations. London: H.M.S.O. 1955. 5 s.

This is a short and fascinating account of a field survey of the food intake and energy output of a group of miners and mining clerks working at the Wellesley Colliery in Fife. The chief aim of the work was to establish the energy expenditure of some of man's many activities.

The experimental subjects were all volunteers. While at work the observer assigned to each made a minute-by-minute record of activity; the rest of the day was equally carefully catalogued by the subject himself.

Energy output was assessed by measuring the rate of oxygen consumption, hitherto a cumbersome procedure using the Douglas bag, but facilitated in this study by the use of the Kofranyi-Michaelis respirometer. This is a portable dry gas-meter with a device for sampling the gas passing through it. Samples were analysed by the Haldane method.

A dietary survey was made at the same time. Each item of food consumed by the subject was weighed and recorded and when possible the exact recipe noted. Calorie values were calculated from M.R.C. tables.

The analysis of results is of much interest. Miners $\frac{1}{2}$ ate more than clerks, a difference accounted for by $c$ their greater physical efforts; away from work their activities were strikingly similar. However, this $\overrightarrow{\vec{\sigma}}$ greater intake was made up of all the main dietary $\overrightarrow{0}$ factors, not carbohydrate. Energy expenditure was $\frac{C}{0}$ linearly related to body weight, save in activity $\frac{\bar{c}}{\bar{c}}$. requiring little body movement, suggesting that $\frac{\sigma}{\sigma}$ much of the energy is required to move the body. $\varnothing$

The whole account is extraordinarily well presented; hetween the lines one perceives the friendly $\overrightarrow{0}$ atmosphere in which the work was done. In simplicity of conception and method, and in clarity and $\overrightarrow{\vec{H}}$ interest of exposition, it must surely be a model of $\mathcal{O}^{\omega}$ how studies of this nature should be performed.

H.K.

\section{A PSYCHOSOMATIC APPROACH TO MEDICINE}

By Desmond O’Neill, M.D., M.R.C.P., D.P.M. Pp. vii + 197. London: Pitman Medical o Publishing Co. Ltd. 1955. 25s.

This is an important little book on a subject as old as medicine itself. The pupils of Hippocrates were taught to examine their patients as livin $\vec{z}$ organisms in an environment, not as isolate biological machines, and the theme of this book that the proper approach to all medicine is psychosomatic one. Today much fuss is made of $\frac{\mathbb{Q}}{1}$ psychosomatic medicine, but to understan medicine at all one must first understand man toto, therefore good medicine is psychosomatic. 흑 의

The doctor first going into practice meets a large number of cases which do not show the orderly diagnostic patterns he has met in medical school and hospital, for it has been estimated that over 20 per cent. of the patients visiting the doctor's surgery are suffering from some physical disorder $\varrho$ intimately associated with emotional tension. The $\overrightarrow{\overrightarrow{0}}$ approach to the patient which this book advocates $\frac{3}{3}$ takes into account both emotional state and physical condition, and in assessing the possible influence $\vec{F}$ which one has upon the other, leads to a global interpretation of causes and effects without which any therapeutic programme will be inadequate.

The volume is extremely well laid out. The bio- $\frac{0}{3}$ dynamic view of disease - that bodily disease reflects maladaptation-is first introduced, followed $\delta$ by an analysis of the stress disorders met with in general practice. The bulk of the work is devoted 을 to a careful description of stress symptoms, illustrated with extracts from suitable case histories and $\frac{D}{0}$ arranged alphabetically for easy reference. The final section gives guidance on suitable therapeutic $N$ methods although limitations of time will generally mean psychiatric referral.

This is an extremely practical book, written $N_{\omega}$ expressly for the general practitioner by an ex- 0 pe ienced worker in the field of psychological $\mathbf{m}$-dicine and designed to be used as a clinician's handbook, a role for which it will be found $\stackrel{\oplus}{\leftrightarrow}$ admirably suited. 